\title{
Review of Adsorption of Fe Metal by Activated Carbon Adsorbent
}

\author{
Fakta Ideal Zega*, Rini Selly, and Moondra Zubir \\ Department of Chemistry, Faculty Of Mathematics annd Natural Sciences, State University of Medan, \\ Jl. Willem Iskandar Pasar V Medan Estate, Medan 20221 Indonesia \\ *Email : faktazega98@gmail.com
}

\begin{abstract}
Many researchers have used activated carbon as adsorbents for the adsorption heavy metal. The aim of present study was to investigate the adsorption properties of activated carbon for the removal of Fe metal. A research has been conducted to determine optimal of stirring time, stirring speed, adsorbent mass and particle size on activated carbon adsorbent in adsorption Fe metal. From the literature survey that increase in stirring time, stirring speed and adsorbent mass enhancing the removal of Fe metal. The results show which is on stirring time 60 minutes, stirring speed 90 radians per minute and adsorbent mass 2 grams have a high adsorption of the heavy metals of iron. Whereas the smaller of particle size enhancing the adsorption of Fe metal. The particle size of 200 mesh is the optimal particle size for adsorption of Fe. Finally, activated carbon showed to be a good potential adsorbent for removing $\mathrm{Fe}$.
\end{abstract}

Keywords: activated carbon, adsorption, adsorbent, $\mathrm{Fe}$

\section{Pendahuluan}

Pencemaran lingkungan dewasa ini akibat limbah pengolahan logam berat yang tidak ramah lingkungan menjadi perhatian seiring berkembangannya industri. Pencemaran oleh limbah logam berat disebabkan kurangnya pengolahan limbah yang dihasilkan dari proses produksi sebelum dibuang ke lingkungan. Limbah dari pengolahan industri kimia pada umumnya mengandung banyak unsur logam berat (seperti Fe, $\mathrm{Cr}, \mathrm{Cu}, \mathrm{Ni}, \mathrm{Zn})^{1}$. Limbah logam berat ini umumnya bersifat karsinogenik dan beracun ${ }^{2}$. Salah satu limbah yang kandungannya sangat tinggiditemukan pada lingkungan adalah limbah besi $(\mathrm{Fe})^{3,4}$.

Proses adsorpsi adalah salah satu dari sekian teknik yang dapat mengurangi atau menghilangkan limbah logam berat pada lingkungan. Proses ini efektif untuk pemisahan ion logam berat dalam air limbah ${ }^{3}$. Metode adsorpsi memanfaatkan kemampuan permukaan adsorben untuk menarik molekul-molekul polutan. Padatan yang terdapat pada permukaan adsorben mampu menarik ion-ion logam baik secara kimia maupun fisika ${ }^{5}$. Metode ini juga merupakan salah satu metode pengolahan air limbah yang paling dikenal karena sangat efisien. Ada beberapa hal yang dapat mempengarui proses adsorpsi, yakni; Luas permukaan adsorben, jenis adsorbat, struktur molekul adsorbat, konsentrasi adsorbat, suhu, $\mathrm{pH}$, kecepatan pengadukan, waktu kontak dan waktu kesetimbangan ${ }^{6}$.

Banyak adsorben dari bahan alam yang telah digunakan dalam metode adsoprsi. Salah satu 
material adsorben yang sering digunakan adalah karbon aktif. Karbon aktif telah banyak digunakan dalam proses pemisahan dan penanganan limbah cairan $^{7,8}$. Bahan karbon berpori ini memiliki daya serap yang tinggi setelah proses karbonisasi ataupun proses aktivasi. Karbon aktif juga memiliki luas permukaan yang tinggi serta struktur pori yakni mikro dan mesopor?. Selain karbon aktif komersil, bahan alam yang dapat dijadikan sebagai karbon aktif untuk proses adsorpsi, antara lain; karbon aktif dari tandan kosong kelapa sawit, ${ }^{10,11}$ karbon aktif dari tempurung kemiri ${ }^{12}$ dan karbon aktif dari sabut kelapa. ${ }^{13}$ Material diatas dapat dimanfaatkan sebagai media penyerapan untuk proses penyerapan limbah logam.

\section{Metodologi Penelitian}

Berdasarkan studi literatur yang telah dilakukan, dapat disimpulkan metodelogi dari beberapa jurnal yang berkaitan pada penelitian adalah sebagai berikut.

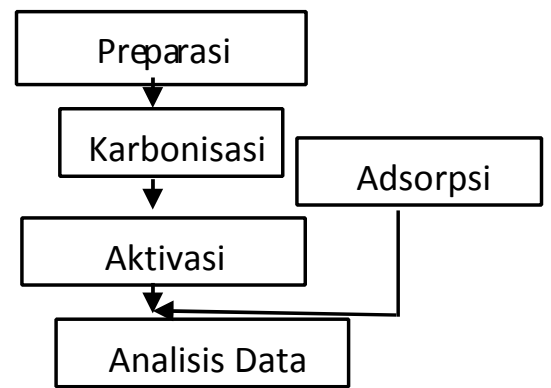

Gambar 1. Diagram alir metodelogi

\subsection{Preparasi Biosorben}

Proses preparasi biosorben dilakukan dengan memotong menjadi ukuran kecil material/bahan yang digunakan sebagai karbon aktif. Proses ini diawali dengan mengeringkan material di bawah sinar matahari atau dengan menggunakan oven pada suhu $105^{\circ} \mathrm{C}$ selama 24 jam kemudian dipotong kecil $(1-2 \mathrm{~cm}){ }^{12}$. Tujuan menjadikan biosorben ukuran kecil untuk memudahkan pada proses karbonisasi serta memperluas permukaan dari biosorben.

Tabel 1. Proses karbonisasi

\begin{tabular}{|l|l|l|l|}
\hline Perkusor & $\begin{array}{l}\text { Suhu } \\
\left({ }^{\circ} \mathrm{C}\right)\end{array}$ & Waktu & Referensi \\
\hline TKKS & 800 & & 8 \\
\hline
\end{tabular}

\begin{tabular}{|l|l|l|l|}
\hline $\begin{array}{l}\text { Tempurung } \\
\text { Kemiri }\end{array}$ & 400 & 1 Jam & 9 \\
\hline Sabut Kelapa & 400 & 2 Jam & 10 \\
\hline
\end{tabular}

\subsection{Aktivasi Karbon}

Pembuatan karbon aktif dilakukan dengan adanya karbonisasi dan diikuti aktivasi. Pola pembentukan struktur pori pada permukaan karbon aktif akan semakin besar berbanding lurus dengna kenaikan suhu dan lama waktu aktivasi.

Tabel 2. Proses aktivasi karbon aktif

\begin{tabular}{|l|l|l|l|}
\hline Perkusor & Aktivator & Waktu & Referensi \\
\hline TKKS & $\mathrm{KOH}$ & & ${ }^{8}$ \\
\hline $\begin{array}{l}\text { Tempurung } \\
\text { Kemiri }\end{array}$ & $\mathrm{H}_{2} \mathrm{SO}_{4}$ & 24 Jam & 9 \\
\hline Sabut Kelapa & $\mathrm{H}_{2} \mathrm{SO}_{4}$ & 24 Jam & 10 \\
\hline
\end{tabular}

\section{Hasil dan Diskusi}

Studi literatur ini bertujuan untuk mengetahui kondisi-kondisi yang dapat mempengaruhi daya adsorpsi karbon aktif pada proses penyerapan logam berat. Studi penyerapan dilakukan terhadap logam berat Besi $(\mathrm{Fe})$.

Hasil literasi menunjukkan penelitian sebelumnya karbon aktif menjadi media yang baik pada proses penyerapan logam berat besi. Penelitian Erman et al., (2016) berhasil mengkarakterisasi dan menguji kemampuan serapan karbon aktif dari tandan kosong kelapa sawit efektif digunakan untuk menyerap logam berat besi. Hal ini juga didukung penelitian lainnya karbon aktif TKKS dapat dimanfaarkan mengadsorpsi logam berat $\mathrm{Fe}^{14}$.

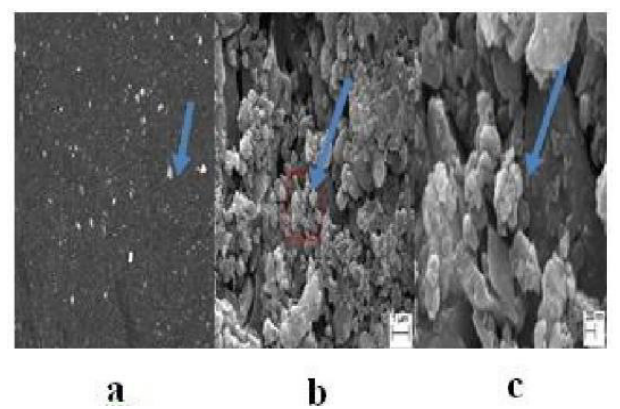

Gambar 2. Hasil SEM sampel perendaman $\mathrm{Fe}$ selama 5 Jam $^{10}$
a. Perbesaran $61 \mathrm{X}$
b. Perbesaran $5000 \mathrm{X}$
c. Perbesaran $20000 \mathrm{X}$ 
Gambar SEM diatas menunjukkan adanya logam berat yang muncul pada adsorben karbon aktif TKKS setelah proses adsorpsi. Kemunculan logam berat ditandai dengan adanya butiran berwarna putih pada permukaan karbon aktif (gambar a). Selain itu logam berat Fe mengisi sturktur pori karbon aktif serta membentuk ikatan (gambar b dan c). Selain itu, karakterisasi karbon aktif menggunakan EDX juga menunjukkan adanya logam Fe yang terserap oleh karbon aktif.

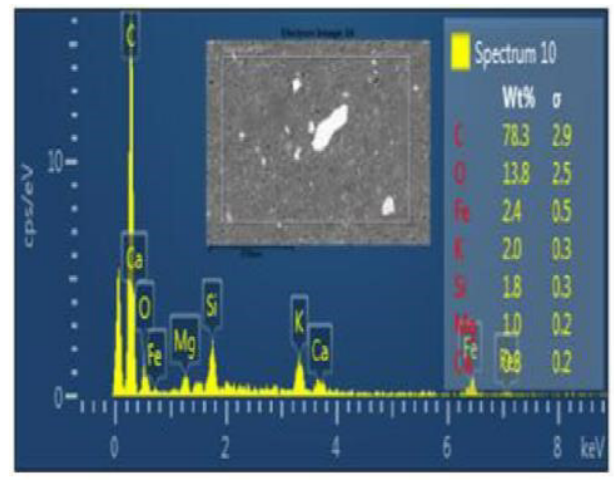

Gambar 3. Kurva Spektrum Uji EDX terhadap Sampel Perendaman Fe Selama 5 $\mathrm{Jam}^{10}$

Telah dilaporkan penelitian Syauqiah dkk, (2011), menunjukkan bahwa semakin lama waktu kontak dan semakin cepat pengadukan akan meningkatkan penyerapan kadar Fe.

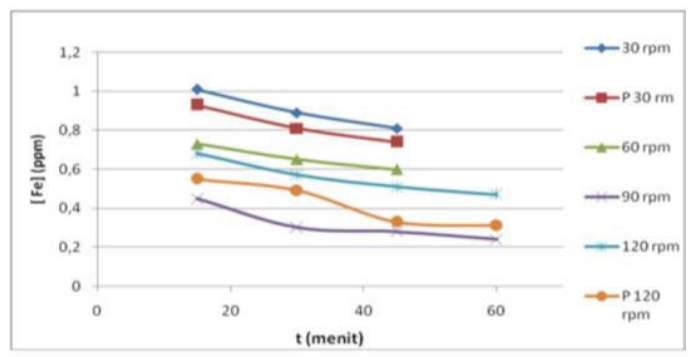

Gambar 4. Hubungan Konsentrasi Fe (ppm) Terhadap Waktu Pengadukan (menit) ${ }^{5}$.

Berdasarkan gambar 2 menunjukan karbon aktif menyerap logam besi dengan optimum pada waktu kontak 60 menit. Semakin lama waktu kontak menyebabkan penyerapan semakin tinggi sehingga semakin banyak logam Fe yang terserap ditandai dengan menurunnya kadar Fe yang tersisa sesuai grafik di atas. Penelitian lainnya menunjukan waktu kontak proses penyerapan $\mathrm{Fe}$ menggunkan karbon aktif adalah 60 menit. ${ }^{15,16,17}$

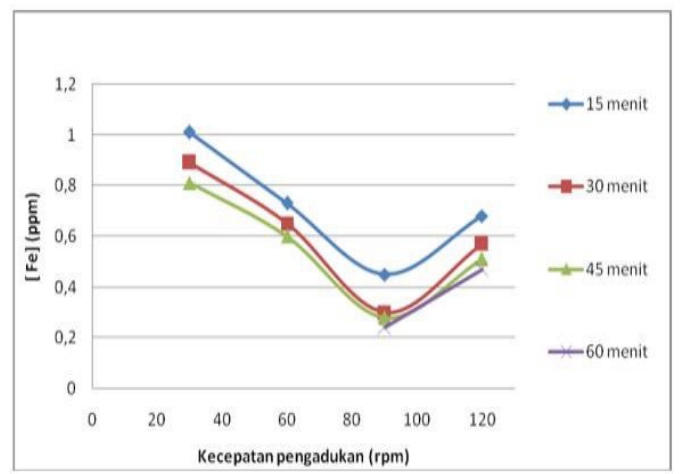

Gambar 5. Hubungan Konsentrasi Fe (ppm) Terhadap Kecepatan Pengadukan (rpm) ${ }^{6}$.

Kecepatan pengadukan mempengaruhi proses adsorpsi. Semakin cepat kecepatan pengadukan akan meningkatkan daya adsorpsi. Kecepatan optimum untuk adsorpsi pada kecepatan pengadukan $90 \mathrm{rpm}$. Pada kecepatan ini karbon aktif menyerap logam Fe dengan maksimal. Akan tetapi, pada kecepatan $120 \mathrm{rpm}$ penyerapan $\mathrm{Fe}$ menurun. Kkecepatan pengadukan yang terlalu tinggi dapat merusak interaksi adsorbat pada proses adsorpsi.

Faktor lain yang mempengaruhi proses adsorpsi logam Fe oleh karbon aktif adalah massa adsorben karbon aktif dan ukuran partikel. Penelitian Istighfarini dkk, (2017), menunjukkan bahwa massa adsorben yang semakin besar akan meningkatkan efisien penyerapan/ adsorpsi. Penambahan massa adsorben akan menyebabkan jumlah tempat untuk mengikat ion logam akan bertambah sehingga semakin banyak logam yang dapat diserap. Sebaliknya, ukuran diameter partikel semakin kecil dapat meningkatkan efisien penyerapan.

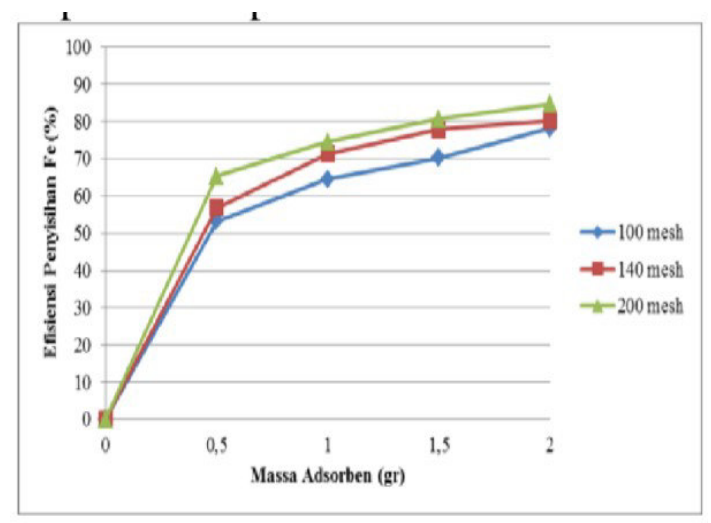

Gambar 6. Pengaruh Massa Adsorben terhadap Penyisihan $\mathrm{Fe}$ 


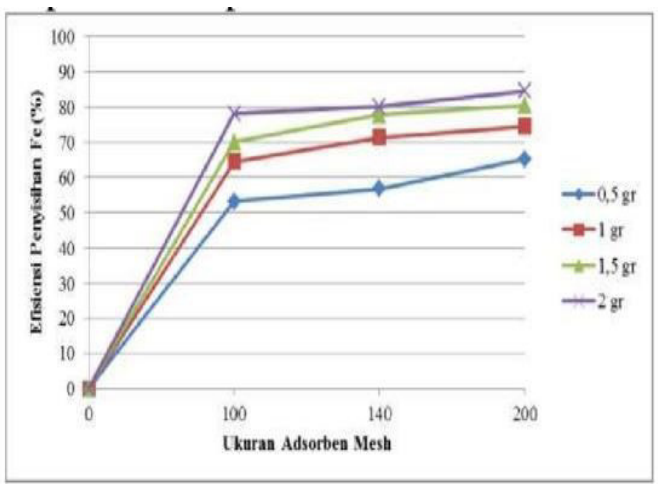

Gambar 7. Pengaruh Ukuran Partikel Adsorben terhadap Penyisihan Fe

Pada gambar 6 dan gambar 7 menunjukan bahwa peningkatan efiensi penyerapan berbanding lurus dengan kenaikan jumlah massa. Efiensi penyerapan tertinggi pada massa adsorben 2 gram. Efisiensi penyerapan pada massa adsorben 2 gram lebih besar $\pm 80 \%$ daripada efisiensi penyerapan pada massa adsorben kurang dari 2 gram. Efisiensi penyerapan juga meningkat seiring dengan semakin kecil ukuran diameter partikel. Ukuran partikel 200 mesh lebih tinggi persen penyerapanya dibandigkan dengan ukuran partikel 100 dan 140 mesh. Ukuran partikel adsorben juga dapat mempengaruhi kapasitas penyerapan logam Fe oleh karbon aktif.

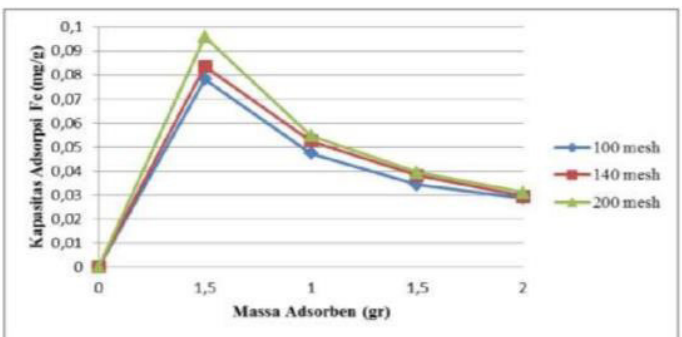

Gambar 8. Perbandingan kapasitas adsorpsi variasi massa dan ukuran partikel untuk logam $\mathrm{Fe}$

Gambar 8 menunjukkan bahwa kapasitas penyerapan tertinggi pada adsorben dengan ukuran partikel 200 mesh. Meningkatnya kapasitas penyerapan ini dikarenakan semakin kecil ukuran partikel maka luas permukaan semakin besar sehingga semakin banyak adsorbat yang terserap. Akan tetapi, kapasitas penyerapan tidak dipengaruhi oleh peningkatan massa adsorben.

\section{Kesimpulan}

Karbon aktif adalah salah satu media yang efektif dijadikan sebagai adsorben untuk mengadorpsi logam berat besi. Proses penyerapan logam besi menggunakan karbon aktif dipengaruhi beberapa hal seperti waktu kontak, kecepatan pengadukan, massa adsorben serta ukuran partikel dari adsorben karbon aktif. Semakin lama waktu kontak dan semakin cepat pengadukan akan meningkatkan kemampuan adsorpsi karbon aktif. Kenaikan jumlah massa akan meningkat efisiensi adsorpsi tetapi tidak mempengaruhi kapasitas penyerapan. Sedangkan ukuran partikel dapat meningkatkan efisiensi dan kapasitas penyerapan. Semakin kecil ukuran diameter partikel menyebabkan luas permukaan semakin besar dan kemampuan adsorpsi menjadi lebih tinggi.

\section{Referensi}

1. F. Asip., R. Mardhiah., \& Husna. (2008). "Uji efektifitas cangkang telur dalam mengadsorbsi ion fe dengan proses batch." $J$. Tek. Kim. 15, pp. 22-26.

2. Z. Abbasi., M. Alikarami., E.R. Nezhad., F. Moradi., \& V. Moradi. (2013). "Adsorptive Removal of $\mathrm{Co}^{2+}$ and $\mathrm{Ni}^{2+}$ by Peels of Banana from Aqueous Solution." Univers. J. Chem. 01(3), pp. 90-95.

3. I.S. Hardyanti., I. Nurani., D.S. Hardjon., E. Apriliani., \& E.A.P. Wibowo. (2017). "Pemanfaatan Silika (SiO2) dan Bentonit sebagai Adsorben Logam Berat Fe pada Limbah Batik." JST (Jurnal Sains Ter). 3, pp. $37-41$

4. Y.D. Efendi., H.I. Nasution., S. Rahmah., \& M. Zubir. (2021, Jan). "Process treatment of heavy metal waste from various type of adsorbent (clay, flay ash, and natural zeolite): A review". Indonesian Journal of Chemical Science and Technology. 04(1), pp. 34-38

5. F.A. Nurdila., N.S. Asri., \& E. Suharyadi. (2015). "Adsorpsi Logam Tembaga (Cu), Besi (Fe), dan Nikel (Ni) dalam Limbah Cair Buatan Menggunakan Nanopartikel Cobalt Ferrite (CoFe2O4)." J. Fis. Indonesia. XIX, pp. 23-27.

6. I. Syauqiah., M. Amalia., \& H.A. Kartini. (2011). “Analisis Variasi Waktu Dan Kecepatan Pengaduk Pada Proses Adsorpsi Limbah Logam Berat Dengan Arang Aktif." Info Tek. 12, pp. 11-20. 
7. T. Hoshimiya., M. Suzuki., T. Takatsu., N. Doi., \& H. Endoh. (2010, March). "Photothermal radiometric time-domain inspection of solid specimen by moving line heat source." Journal of Physics: Conference Series. 214(1), pp. 1-4

8. L. Fadillah., Jasmidi., R. Selly., \& M. Zubir. (2021, Jan). "Water purification process uses adsorbents from natural material". Indonesian Journal of Chemical Science and Technology. 04(1), pp. 42-44.

9. A.A. Noer., Awitdrus., \& U. Malik. (2014). "Pembuatan Karbon Aktif Dari Pelepah Kelapa Sawit Menggunakan Aktivator H2O Sebagai Adsorben." Jom Fmipa 1, 42-47.

10. T. Erman., M.W. Sinta., \& Sugianto. (2016). "Pemanfaatan Potensi Tandan Kosong Kelapa Sawit Sebagai Karbon Aktif Untuk Pembersih Air Limbah Aktivitas Penambangan Emas." $J$. Komun. Fis. Indones. 13(13), pp. 852-858.

11. R.A.F. Lubis., H.I. Nasution., \& M. Zubir. (2020, July). "Production of activated carbon from natural sources for water purification". Indonesian Journal of Chemical Science and Technology. 03(2), pp. 67-73

12. P. Nunik., \& D.G. Okayadnya, (2013). "Penyisihan Logam Besi (Fe) Pada Air Sumur Dengan Karbon Aktif Dari Tempurung Kemiri." Envirotek J. Ilm. Tek. Lingkung. 5, pp. 33-41.

13. S.A.E. Istighfarini., S. Daud., \& Hs, E. (2017). "Pengaruh Massa dan Ukuran Partikel Adsorben Sabut Kelapa Terhadap Efisiensi Penyisihan Fe Pada Air Gambut." Jom FTEKNIK 4, pp. 1-8.

14. A.G. Haji., G. Pari., M. Nazar., \& Habibati. (2013). "Characterization of activated carbon produced from urban organic waste." Int. J. Sci. Eng. 5, pp. 89-94.

15. A.R. Hidayu., N.F. Mohamad., S. Matali., \& A.S.A.K. Sharifah. (2013). "Characterization of activated carbon prepared from oil palm empty fruit bunch using BET and FT-IR techniques." Procedia Eng. 68, pp. 379-384.

16. S. Hashemian., S.H. Hosseini., H. Salehifar., \& K. Salari. (2013). "Adsorption of Fe(III) from Aqueous Solution by Linde Type-A Zeolite." Am. J. Anal. Chem. 04, pp. 123-126.

17. S.S. Abuzar \& T. Edwin. (2015, Jan). "Kemampuan Batu Apung Sebagai Adsorben
Penyisihan Logam Besi (Fe) Air Tanah." $J$. Teknik Lingkungan UNAND. 12(1), pp. 1-9. 